\title{
Immobilised- $\beta$-galactosidase Catalysed Conversion of Lactose on the Membrane Surface
}

\author{
Fadzil Noor Gonawan, Azlina Harun Kamaruddin, ${ }^{*}$ Mohamad Zailani Abu Bakar and \\ Khairiah Abd Karim \\ School of Chemical Engineering, Engineering Campus, Universiti Sains Malaysia, \\ 14300 Nibong Tebal, Pulau Pinang, Malaysia \\ *Corresponding author: chazlina@usm.my
}

Published online: 25 February 2018

To cite this article: Gonawan, F. N. et al. (2018). Immobilised- $\beta$-galactosidase catalysed conversion of lactose on the membrane surface. J. Phys. Sci., 29(Supp. 1), 49-56, https://doi.org/10.21315/jps2018.29.s1.7

To link to this article: https://doi.org/10.21315/jps2018.29.s1.7

\begin{abstract}
Galacto-oligosaccharides (GOS) can be synthesised via $\beta$-galactosidase $(\beta-G a l)$ catalysed conversion of lactose. The reaction process was carried out in the membrane reactor system to improve the conversion by partial separation of the products and galactose inhibitor. The reaction rate was determined by the concentration of the solutes on the biocatalytic membrane and it was varied by manipulating the transmembrane pressure (TMP). The yield of GOS was highest at a TMP $=0.5$ bar. It was found that the formation of gel layer at higher TMP $(>0.5$ bar) reduced the mass transfer of solutes through the biocatalytic membrane. Therefore, the reaction rates were decreased although the separation of galactose inhibitor was improved. Hence, it is concluded that the mass transfer of solute is the determining factor to obtain a high yield of GOS.
\end{abstract}

Keywords: Lactose, galacto-oligosaccharides, $\beta$-galactosidase, membrane, catalysed conversion

\section{INTRODUCTION}

Lactose (galactosyl $\beta(1-4)$ glucose) is a natural substrate for $\beta$-Gal which hydrolyses $\beta(1-4)$ linkage and reduces it to glucose and galactose. In fact, $\beta$-Gal also exhibits transgalactosylation activity by transferring galactose belonging to the hydrolysed saccharide to the galactose moiety of other saccharides, which results in the formation of galacto-oligosaccharides (GOS). The conversion of lactose to GOS by $\beta$-Gal involves a two-step reaction, which are hydrolysis and transgalactosylation. There are two known limitations in the reaction process 
which reduces the formation of GOS. Numerous articles have reported that monosaccharides by-products formed from lactose hydrolysis inhibit the $\beta$-Gal and reduce the catalytic activity. ${ }^{1}$ In addition, the glycosidic bond (between glucose and galactose) in the GOS structure is also susceptible to hydrolysis by the $\beta$-Gal and thus reducing the yield.

Several strategies have been suggested to improve the yield of GOS. The easiest approach is by increasing the initial substrate concentration to drive the reaction toward the formation of $\beta$-Gal-galactosyl complex and GOS. ${ }^{2}$ It is also suggested that the products should be removed from the reaction system (i.e., via membrane separation) once it was formed in a continuous reaction to avoid hydrolysis side reaction and reduce the inhibition effect. $^{3}$

In the present work, lactose conversion is carried out in the enzymatic hollow fibre membrane reactor (EHFMR) as depicted in Figure 1. The study emphasises on the effect of solute mass transfer on the reaction rate profile.

(a)

ß-Gal
Glucose
Galactose
Lactose
Galacto-oligosaccharides

\section{EXPERIMENTAL}

\subsection{Biocatalytic Reaction in the EHFMR}

The membrane is a hollow fibre with a high surface to volume ratio compared to flat sheet membrane. The $\beta$-Gal was immobilised on the lumen side of the membrane via covalent bonds. ${ }^{4}$ The reaction occurred at $55^{\circ} \mathrm{C}$ and with a feed flow rate of $5 \mathrm{ml} \mathrm{min}{ }^{-1}$. The TMP or average pressure differences between the lumen and permeate side of the membrane was generated ( 0.4 to 0.8 bar) by regulating pressure regulator valve. 


\subsection{Chemical Analysis}

The saccharides presence in the sample was analysed using liquid chromatography equipped with RCM monosaccharide $8 \% \mathrm{Ca}^{2+}$ column and refractive index detector. The fractionation of saccharides was performed at $1 \mathrm{ml} \mathrm{min}{ }^{-1}$ and $85^{\circ} \mathrm{C}$. The concentration of the saccharides was evaluated by comparing the peak area with the external standard.

\subsection{Kinetic Model of Reaction}

The $\beta$-gal-catalysed conversion of lactose involves several reaction processes that lead to the formation of glucose, galactose and various types of GOSs. In this particular work, the following reactions have been considered.

$$
\begin{aligned}
& {[E]+[L a c] \underset{k_{-1}}{\stackrel{k_{1}}{\rightleftharpoons}}[E l a c] \stackrel{k_{P 1}}{\rightarrow}\left[E^{\prime} G a l\right]+[G l u]} \\
& {\left[E^{\prime} G a l \stackrel{k_{P 2}}{\rightarrow}[E]+[G a l]\right.} \\
& {\left[E^{\prime} G a l\right]+[L a c] \underset{k_{-2}}{\stackrel{k_{2}}{\rightleftharpoons}}\left[E^{\prime} l a c\right] \stackrel{k_{P 3}}{\rightarrow}[E]+\left[G o s_{3}\right]} \\
& {\left[E^{\prime} G a l\right]+\left[G o s_{3}\right] \underset{k_{-4}}{\stackrel{k_{4}}{\rightleftharpoons}}\left[E^{\prime} G o s_{3}\right] \stackrel{k_{P 4}}{\rightarrow}[E]+\left[\operatorname{Gos}_{4}\right]} \\
& {[E]+\left[G o s_{3}\right] \underset{k_{-3}}{\stackrel{k_{3}}{\rightleftharpoons}}\left[E G o s_{3}\right] \stackrel{k_{h 4}}{\rightarrow}[E]+[G b i]+[G l u]}
\end{aligned}
$$

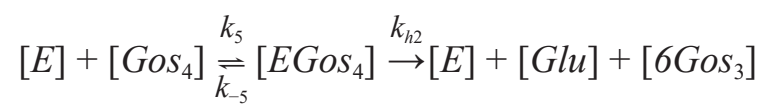

$$
\begin{aligned}
& {[E]+[G a l] \underset{k_{-6}}{\stackrel{k_{6}}{\rightleftharpoons}}[E G a l]}
\end{aligned}
$$

Therefore, the rate of reactions are given by:

$$
\begin{aligned}
& -V_{L a c}=-\frac{d[L a c]}{d t}=k_{P 1}[\text { Elac }]+k_{P 3}\left[E^{\prime} l a c\right] \\
& V_{G l u}=\frac{d[G l u]}{d t}=k_{P 1}[E l a c]+k_{h 1}\left[E_{G o s_{3}}\right]+k_{h 2}\left[E_{G o s_{4}}\right]
\end{aligned}
$$




$$
\begin{aligned}
& V_{G a l}=\frac{d[G a l]}{d t}=k_{P 1}\left[E^{\prime} G a l\right] \\
& V_{G_{3}}=\frac{d\left[\mathrm{Gos}_{3}\right]}{d t}=k_{P 3}\left[E^{\prime} l a c\right]+k_{h 1}\left[E_{G o s_{3}}\right]+k_{P 4}\left[E^{\prime} \operatorname{Gos}_{3}\right] \\
& V_{G^{\prime} s_{4}}=\frac{d\left[G o s_{4}\right]}{d t}=k_{P 5}\left[E^{\prime} G o s_{3}\right]-k_{h 2}\left[E G o s_{4}\right]
\end{aligned}
$$

The production of minor products of galactosyl galactose ([Gbi] and ([6Gos $]$ ) was assumed negligible. Equations 8-12 are solved by normalisation with a total of enzyme presence in the reaction system and the terms of enzyme-substrate complexes are substituted with free enzyme terms. The values of the parameters were obtained by nonlinear regression of the equations with the experimental data.

\subsection{Coupled Mass Transfer-reaction Kinetic Model}

The governing mass balance and continuity equations in the membrane reactor system are as follows: ${ }^{5}$

At the retentate (lumen) side:

$$
\begin{aligned}
& \nabla \cdot\left(-D_{o, i} \nabla C_{i}\right)+v \cdot \nabla C_{i}=0 \\
& J_{i}=-D_{o, i} \nabla C_{i}+v \nabla C_{i}
\end{aligned}
$$

At biocatalytic membrane layer:

$$
\begin{aligned}
& \nabla .\left(-D_{m, i} \nabla C_{i}\right)=R_{i} \\
& \left.J_{i}=-D_{m, i} \nabla C_{i}\right)
\end{aligned}
$$

At permeate (shell) site:

$$
\begin{aligned}
& \nabla \cdot\left(-D_{o, i} \nabla C_{i}\right)+v \cdot \nabla C_{i}=0 \\
& J_{i}=-D_{o, i} \nabla C_{i}+v C_{i}
\end{aligned}
$$

where $D_{o, i}$ and $D_{m, i}$ denote the diffusion coefficients $\left(\mathrm{m}^{2} \mathrm{~s}^{-1}\right)$ of the solute on the liquid phase layer and on the biocatalytic membrane layer, respectively. $R_{i}$ is the reaction rate of the solutes. $J_{i}\left(\mathrm{~mol} \mathrm{~m}^{-2} \mathrm{~s}^{-1}\right)$ is the molar flux. Meanwhile, $C_{i}\left(\mathrm{~mol} \mathrm{~m}^{-3}\right)$ is the solute concentration and $v$ is the velocity vector $\left(\mathrm{m} \mathrm{s}^{-1}\right)$. 


\section{RESULTS AND DISCUSSION}

\subsection{The Effect of TMP}

Table 1 shows that the conversion of lactose to GOS is affected by TMP. The highest GOS yield and lactose conversion were achieved at a TMP $=0.5$ bar. The reaction rates are supposed to improve when external pressure is applied due to a faster mass transfer rate of the solutes or substrates to the catalytic site of $\beta$-Galimmobilised on the membrane surface. However, this conclusion is not met with decreasing trend of GOS yield and lactose conversion at TMP higher than 0.5 bar.

Table 1: The effect of TMP on GOS yield, conversion and separation factor.

\begin{tabular}{ccccc}
\hline \multirow{2}{*}{ TMP (bar) } & GOS yield $^{\mathrm{a}}(\%)$ & Conversion $^{\mathrm{b}}(\%)$ & \multicolumn{2}{c}{ Separation factor $\left(S_{f, i}\right)^{\mathrm{a}}$} \\
\hline 0.4 & 4.2 & 14.3 & GOS & Gal \\
0.5 & 5.5 & 25.1 & 0.8 & 1.1 \\
0.6 & 3.8 & 10.3 & 0.5 & 1.4 \\
0.8 & 2.7 & 7.6 & 0.3 & 2.0 \\
\hline
\end{tabular}

Notes:

${ }^{a}$ Gos yield $=\frac{C_{G o s 3}+C_{G o s 4}}{C_{\text {Lac,o }}}$, where $C_{i}$ is a concentration of the species.

${ }^{b}$ Conversion $=\frac{C_{L a c}}{C_{L a c, o}} \times 100 \%$, where $C_{\text {Lac,o }}$ is the initial lactose concentration.

${ }^{c} S_{f, i}=\frac{C_{p, i} / C_{r, i}}{C_{p, s} / C_{r, s}}$ where $p$ is permeate, $r$ is retentate, $i$ is product species and $s$ is the substrate.

The yield of GOS can be increased with high initial concentration of lactose as proven in several reports. ${ }^{2}$ In the present work, the amount of lactose adsorbed to the catalytic site of $\beta$-Gal is determined by the mass transfer rate of the lactose through the biocatalytic membrane. It is suggested that the yield of GOS is highest at a TMP $=0.5$ bar because the mass transfer rate of lactose is initially increased and then decreased when the TMP $>0.5$ bar. The mass transfer or permeation of solutes such as lactose through the membrane can be decreased even with high external pressure when gel layer is formed on the membrane layer. This phenomenon occurred due to larger back diffusion force since the larger solutes are sieved by the pores. Thus, the adsorption of lactose to the catalytic sites is interrupted.

Meanwhile, the separation factor of galactose inhibitor was gradually improved with higher TMP and the $\beta$-Gal is expected to give a better catalytic performance 
which is not indicated. This result highlights that the influence of mass transfer of the solutes to the biocatalytic membrane surface is significant for the reaction. Thus, the subsequent study on the effect of mass transfer on the rate of reaction was conducted with the consideration of gel layer formation.

\subsection{Reaction Rates Profile}

The reaction rate profiles of the saccharides in the reaction system were solved via $\mathrm{COMSOL}^{\circledR}$ software. Figure 2(a) shows the consumption rate of lactose in the axial direction of the fibre membrane, whereas Figures 2(b)-2(e) show the production rates of glucose, galactose, trisaccharides $\left(\mathrm{Gos}_{3}\right)$ and tetrasaccharides $\left(\mathrm{Gos}_{4}\right)$. Generally, the consumption and production rates of substrate and products respectively increase when the TMP is increased to 0.5 bar. Subsequently, the reaction rates decrease with further increase of TMP due to back diffusion of lactose from the biocatalytic membrane domain. This phenomenon restricted the adsorption of lactose to the catalytic site and thus the reaction rate reduced. The concentration profile of lactose in the axial direction of the biocatalytic membrane is shown in Figure 2(f). As expected, the highest concentration of lactose on the biocatalytic membrane surface is achieved at a $\mathrm{TMP}=0.5$ bar which explains high GOS yield.

The reaction rates gradually increased in the axial direction of the fibre membrane, whereby highest rates are indicated at the outlet side for all of the saccharides. This result is suggested due to axial flow which pulls most of the substrate toward the outlet side of the fibre membrane. Due to this reason, it is possible that the $\beta$-Gal immobilised on the outlet side of the fibre membrane will be having a shorter half-life compared to the $\beta$-Gal immobilised on the inlet side. Therefore, the inlet direction of the hollow fibre membrane reactor should be alternated in order to maximise the catalytic activity of the immobilised $\beta-G a l$.

\section{CONCLUSION}

The reaction rate of $\beta$-Gal-catalysed conversion of lactose on the membrane surface was solved via a coupled model of mass transfer-reaction kinetic. The formation of gel layer at high TMP reduces the mass transfer of the substrate to the bio-catalytic layer and reaction rates. The mass transfer is the limiting factor for a reaction in the EHFMR system. Therefore, further study needs to be carried out to optimise the reaction system to obtain high productivity of GOSs. 
(a)

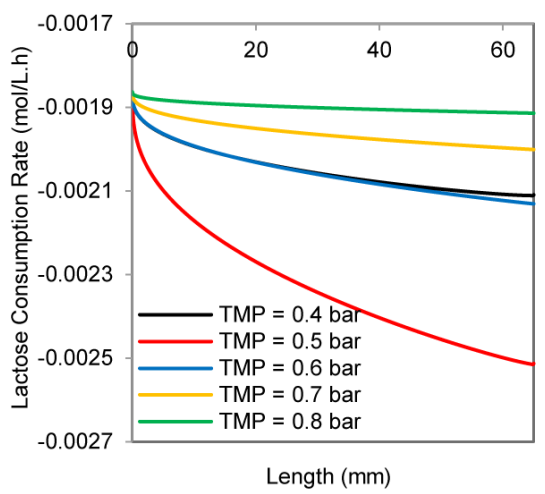

(c)

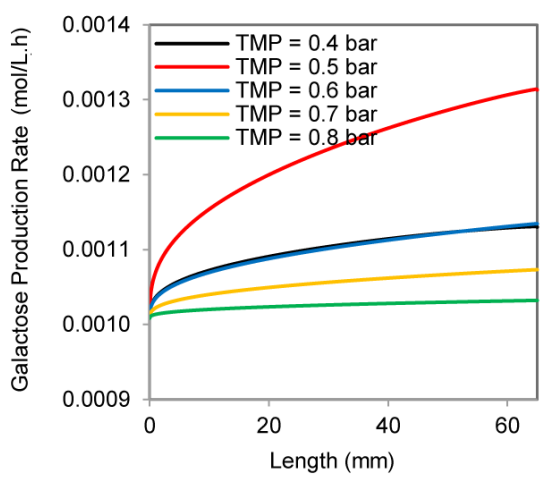

(e)

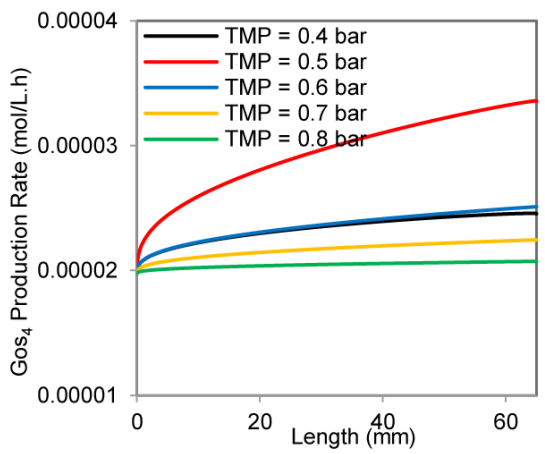

(b)

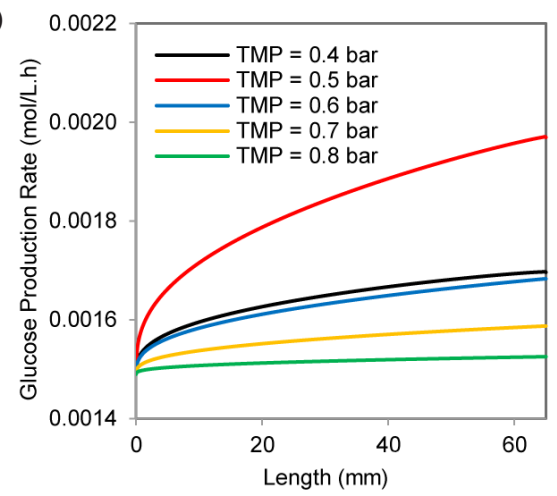

(d)

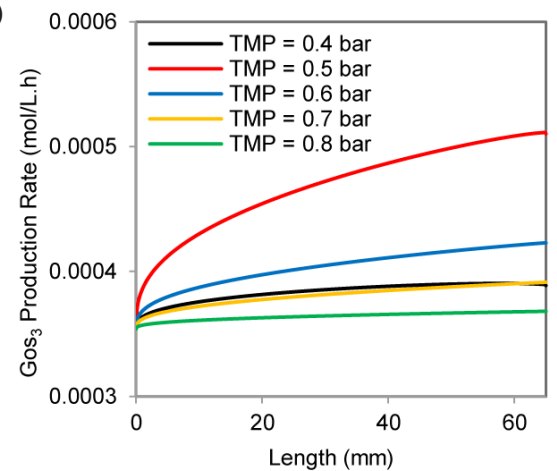

(f)

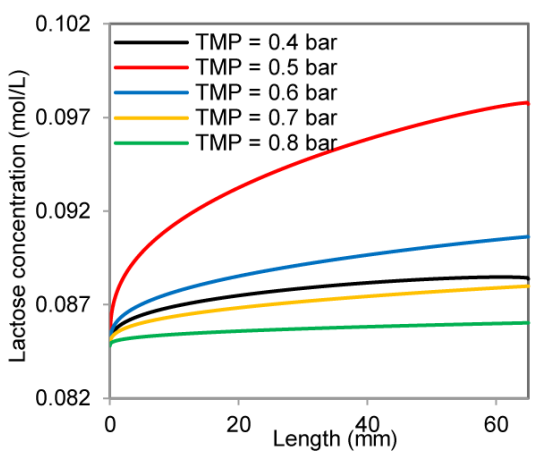

Figure 2: The reaction rate profiles of (a) lactose, (b) glucose, (c) galactose, (d) trisaccharides $\left(\mathrm{Gos}_{3}\right)$ and (e) tetrasaccharides $\left(\mathrm{Gos}_{4}\right)$ on the membrane surface. Whereas, (f) is the concentration profile of lactose on the membrane surface. 


\section{ACKNOWLEDGEMENTS}

The authors would like to acknowledge the Malaysian Ministry of Science, Technology and Innovation (MOSTI: PJKIMIA/6013387) as well as Universiti Sains Malaysia (USM) for their support in this research.

\section{REFERENCES}

1. Park, A-R. \& Oh, D-K. (2010). Galacto-oligosaccharide production using microbial $\beta$-galactosidase: Current state and perspectives. Appl. Microbiol. Biotechnol., 85(5), 1279-1286, https://doi.org/10.1007/s00253-009-2356-2.

2. Huerta, L. M. et al. (2011). Synthesis of galacto-oligosaccharides at very high lactose concentrations with immobilized $\beta$-galactosidases from Aspergillus oryzae. Process. Biochem., 46(1), 245-252, https://doi.org/10.1016/j. procbio.2010.08.018.

3. Nath, A., Bhattacharjee, C. \& Chowdhury, R. (2013). Synthesis and separation of galacto-oligosaccharides using membrane bioreactor. Desalin., 316, 31-41, https://doi.org/10.1016/j.desal.2013.01.024.

4. Gonawan, F. N. et al. (2016). Simultaneous adsorption and fixation of aspergillus oryzae $\beta$-Galactosidase on polyelectrolyte-layered polysulfone hollow-fiber membrane. Ind. Eng. Chem. Res., 55(1), 21-29, https://doi. org/10.1021/acs.iecr.5b02541.

5. Nagy, E. (2012). Basic equations of the mass transport through a membrane layer. London: Elsevier. 